\title{
Avaliação rápida de rios e nascentes como instrumento de análise ambiental urbana e rural
}

Este trabalho teve como objetivo aplicar dois protocolos de avaliação rápida para classificação dos cursos d'água e das nascentes da Bacia Hidrográfica do Córrego dos Pires em Jaú/SP. Esta bacia possui $15,45 \mathrm{~km}^{2}$ de área total, sendo $79,6 \%$ no perímetro urbano e $51,8 \%$ apresentando alto grau de impermeabilização do solo. Para o estudo de caso foram selecionados o protocolo de avaliação rápida de rios adaptado por Callisto et al. (2002) e o protocolo de avaliação rápida de nascentes proposto por Gomes et al. (2005). Em relação ao grau de preservação das cinco nascentes avaliadas uma foi classificado como "boa", uma como "regular" e três como "ruins". Para a avaliação dos trechos dos cursos d'água foi proposta uma recategorização em sete níveis, permitindo desta forma a diferenciação minuciosa do estado de cada trecho. As categorias ou estado dos trechos definidos na proposta foram: "natural", "seminatural", "alterado", "muito alterado", "impactado", "altamente impactado" e "degradado". Dos doze trechos avaliados um foi enquadrado como "natural", dois como "seminaturais", dois como "alterados", dois como "muito alterados" e cinco como "impactados". Os resultados demonstraram a eficácia na utilização destes protocolos na avaliação ambiental da bacia hidrográfica. As situações encontradas e a classificação quanto aos impactos ambientais macroscópicos nas nascentes e em cada trecho dos cursos d'água podem ser úteis nos processos de tomada de decisão para a gestão ambiental urbana e a sustentabilidade das cidades.

Palavras-chave: Avaliação Ambiental; Curso d'água; Nascentes; Bacia Hidrográfica.

\section{Rapid evaluation of rivers and rivers as an instrument of urban and rural environmental analysisabstract}

\begin{abstract}
The objective of this work was to apply two rapid assessment protocols to classify the watercourses and the springs of the Córrego dos Pires Hydrographic Basin in Jaú/SP. This basin has $15,45 \mathrm{~km}^{2}$ of total area, being $79,6 \%$ in the urban perimeter and $51,8 \%$ presenting a high degree of waterproofing of the soil. For the case study, were selected the rapid river evaluation protocol adapted by Callisto et al. (2002) and the rapid spring assessment protocol proposed by Gomes et al. (2005). In relation to the degree of preservation of the five springs evaluated one was classified as "good", one as "regular" and three as "bad". For the evaluation of the stretches of the watercourses it was proposed a recategorization in seven levels, allowing in this way the detailed differentiation of the state of each stretch. The categories or state of the sections defined in the proposal were: "natural", "seminatural", "altered", " highly altered ", "impacted", " highly impacted" and "degraded". Of the twelve evaluated one was framed as "natural", two as "seminaturals", two as "altered", two as " highly altered " and five as "impacted". The results demonstrated the effectiveness of using these protocols in the environmental assessment of the river basin. The situations encountered and the classification of the macroscopic environmental impacts in the springs and in each stretch of watercourse can be useful in decision-making processes for urban environmental management and the sustainability of cities.
\end{abstract}

Keywords: Environmental Assessment; Watercourse; Spring; Watershed.

\section{Topic: Engenharia de Recursos Hídricos}

Reviewed anonymously in the process of blind peer

Jozrael Henriques Rezende

Universidade Federal de São Carlos, Brasil http://lattes.cnpq.br/4418756295562718 jozrael.rezende@fatec.sp.gov.br

Melissa Valiente de Luca

Universidade Estadual de Campinas, Brasil http://lattes.cnpq.br/9870026906198249 mel luca@hotmail.com

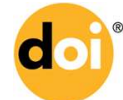

DOI: $10.6008 / S P C 2179-6858.2017 .004 .0008$
Received: 07/07/2017

Approved: 08/10/2017
Referencing this:

REZENDE, J. H.; LUCA, M. V.. Avaliação rápida de rios e nascentes como instrumento de análise ambiental urbana e rural. Revista IberoAmericana de Ciências Ambientais, v.8, n.4, p.85-100, 2017. DOI: http://doi.org/10.6008/SPC2179-6858.2017.004.0008 


\section{INTRODUÇÃO}

Os rios são escoadouros naturais das áreas de drenagens de uma bacia hidrográfica (TOLEDO et al., 2002). Além disto, segundo Rodrigues et al. (2012), possuem característica dinâmica e grande variabilidade e complexidade de parâmetros bióticos e abióticos. Essa complexidade se deve a geologia, ao tamanho e forma da bacia hidrográfica, ao uso do solo e das condições climáticas do local.

Gorski (2010) enfatiza a importância do equilíbrio e da integridade dos componentes físicos e biológicos na dinâmica dos cursos d'água. A vegetação ciliar, o leito, suas características de largura e profundidade, poços ou depressões, soleiras, meandros, planícies de inundação ou várzeas são elementos que desempenham papéis específicos no ecossistema fluvial, como o transporte da água e dos sedimentos, armazenamento ou transbordamento das águas de enchentes, além de servirem como habitats terrestres e aquáticos da fauna e da flora.

Desde sempre, o desenvolvimento humano está intimamente relacionado aos recursos hídricos, pois além de insumo vital, a água possui usos múltiplos como abastecimento, irrigação, transporte, geração de energia, entre outros. As margens de rios são ainda ocupadas e utilizadas pelos homens desde tempos imemoriais. Os rios e suas águas possuem, portanto, papel fundamental na manutenção da qualidade de vida humana (RODRIGUES et al., 2012; FIRMINO et al., 2011).

Com o passar dos tempos, o crescimento populacional, a industrialização e o intenso processo de urbanização, desequilibraram o meio ambiente ocasionando impactos negativos consideráveis, inclusive aos recursos hídricos. Por se tratar de um processo que ocorreu relativamente rápido, a maioria dos casos de urbanização se deu de forma desordenada e massificada, sem planejamento territorial adequado e sem preocupação com o manejo das águas pluviais (FAXINA et al., 2012). Tais constatações são apresentadas também por Otsuka (2013), que ressalta ainda a deterioração da qualidade das águas fluviais e a ampliação dos problemas de alagamentos em áreas urbanas com consequências de ordem social, econômica e ecológica.

Ações antrópicas vêm alterando constantemente os cursos d'água inseridos em zonas urbanas. Inúmeros impactos observados nos cursos d'água nas cidades são causados pelo processo de urbanização, tais como alterações nas vazões máximas e mínimas, erosão do talude fluvial, assoreamento, degradação da qualidade da água, além das alterações causadas nas condições ambientais à jusante (TUCCl et al., 2006; RADTKE, 2015).

Fogaroli (2013) aponta que o modelo de desenvolvimento urbano atual gera diversos problemas socioambientais, causando prejuízos às cidades e seus habitantes, como o aumento do escoamento superficial causado pela impermeabilização do solo, canalizações e retificações de rios, exposição do solo a processos erosivos, concentração de escoamento superficial sem projetos de engenharia adequados, entre outros.

Tucci et al. (2006) calcula que a vazão média de cheia pode ser até sete vezes maior com a impermeabilização do solo. Citam ainda a redução do tempo de concentração (tc) das bacias hidrográficas 
urbanas devido aos sistemas de drenagem tradicionais, ou seja, as alterações na superfície das bacias hidrográficas por processos de urbanização levam a impactos expressivos no escoamento superficial.

Este cenário se repete em grande parte das cidades brasileiras. Faxina et al. (2012) verificaram que quanto maior a cidade, maiores serão seus problemas, pois o crescimento desordenado e a taxa de impermeabilização serão maiores. Faxina et al. (2012) ainda defende que só essa constatação já justificaria a adoção de bacias hidrográficas, sejam elas urbanas ou em processo de urbanização, como unidades básicas de gestão, principalmente em relação ao manejo das águas pluviais. Otsuka (2013) vai além, pois para a autora os estudos ecológicos devem adotar uma abordagem mais abrangente em relação às bacias hidrográficas, visando entender o meio através da interação entre seus componentes.

Rebouças (2006) constatou a necessidade de monitoramento das alterações ambientais focado nos impactos sobre os ecossistemas hídricos, tendo em vista que a qualidade e a disponibilidade dos recursos hídricos é inteiramente influenciada pelas atividades antrópicas que modificam a composição da água e o balanço hídrico. Para Rodrigues et al. (2012), a avaliação ambiental de rios é uma ferramenta importante no monitoramento destes ecossistemas e gera informações relevantes sobre suas atuais condições.

A solução dos problemas socioambientais oriundos da má gestão dos recursos hídricos, da drenagem urbana e do saneamento passa inicialmente pelo desenvolvimento e utilização de metodologias adequadas para diagnosticar o estado do ambiente (BUSS et al., 2003). Rodrigues et al. (2008) e Radtke (2015) descrevem em seus trabalhos a dificuldade de pesquisadores na obtenção de dados da qualidade ambiental e da situação dos cursos d'água, devido à ausência de monitoramento. Fica evidente a necessidade de uso de uma ferramenta eficiente, eficaz, confiável e de baixo custo para o monitoramento dos recursos hídricos, auxiliando na sua gestão (FARIA et al., 2013; RODRIGUES et al., 2008).

Nesse contexto, surgiram os protocolos de avaliação rápida (PARs), que avaliam qualitativamente os cursos d'água superficiais, realizando uma análise macroscópica integrada do ecossistema, de maneira simples, fácil, rápida e com baixo custo (BIZZO et al., 2014; MINATTI-FERREIRA et al., 2006; RODRIGUES et al., 2008; VARGAS et al., 2012; CARVALHO et al., 2014; OLIVEIRA et al., 2015; RADTKE, 2015). Callisto et al. (2001) ressalta que, além de ser uma ferramenta importante para o monitoramento ambiental, os PARs auxiliam nas tomadas de decisões relacionadas aos problemas identificados durante a avaliação e até mesmo na priorização das intervenções (HENRIQUES NETO, 2010; VARGAS et al., 2012).

Outro ponto favorável à utilização dos PARs, é que a sua aplicação pode ser realizada por profissionais especializados, estudantes, agentes sociais ou até voluntários, desde que previamente treinados (BIZZO et al., 2014; RODRIGUES et al., 2008). Esta ferramenta é utilizada também em atividades de pesquisa e ensino com excelentes resultados no que diz respeito a melhoria da percepção sobre a conservação e a degradação dos corpos hídricos (CALLISTO et al., 2002, CARVALHO et al., 2014). Buss et al. (2003) salienta que uma grande vantagem dos PARs é sua linguagem acessível, o que facilita a comunicação dos resultados de monitoramento ambiental não apenas aos respectivos gestores, mas também ao público em geral, promovendo assim o envolvimento da sociedade. 
Bizzo et al. (2014) destaca que, muitas vezes, torna-se fundamental a adaptação dos protocolos de avaliação rápida devido a diversidade dos ecossistemas fluviais quanto a vegetação, clima, relevo, solo, substrato do fundo, inclinação do talude, entre outros aspectos. O desafio para um bom diagnóstico é a seleção e a criação de indicadores que caracterizem o estado real da área avaliada, fornecendo informações úteis à conservação e a recuperação ambiental (OTSUKA, 2013).

A aplicação dos protocolos de avaliação rápida de rios e nascentes representam a primeira etapa para a elaboração de propostas de revitalização de cursos d'água e de suas nascentes, dentro do contexto da bioengenharia e da renaturalização. Estas técnicas surgem neste momento como alternativas para reverter a degradação ambiental de grande parte dos cursos d'água urbanos no Brasil, já que visam reintegrar os cursos d'água à paisagem urbana, melhorando a qualidade de suas águas e sua estética e permitindo à recuperação de hábitats e da biodiversidade destes ecossistemas (SELLES et al., 2001).

Neste contexto, a escolha da Bacia Hidrográfica do Córrego dos Pires, Jaú/SP, como objeto de estudo deste trabalho, se deu por se tratar de uma bacia com $79,6 \%$ de sua área no perímetro urbano, sendo que 51,8\% da área total apresenta alto grau de impermeabilização do solo. A bacia também apresenta características distintas, com áreas relativamente conservadas até áreas impactadas próximas à foz. Além disso, suas nascentes e margens possuem fácil acesso e a bacia tem sido utilizada como instrumento de ensino-aprendizagem em disciplinas e cursos relacionados ao meio ambiente para os ensinos fundamental, médio, técnico e superior no município.

O presente trabalho teve como objetivo aplicar dois modelos de protocolo de avaliação rápida, um para nascentes e outro para rios, a fim de caracterizar seus níveis de preservação ou de degradação. $O$ estudo também visa colaborar na valorização dos PARs como ferramentas de monitoramento e gestão ambiental, que segundo Krupek (2010) e Minatti-Ferreira et al. (2006) são essenciais para os órgãos gestores dos recursos naturais.

A avaliação ambiental é de suma importância para o planejamento e implantação de programas de manutenção, preservação e recuperação de ambientes, afinal a revitalização de bacias hidrográficas é possível somente após a compreensão dos distúrbios naturais e/ou antrópicos que estão afetando suas funções ecológicas (HENRIQUES NETO, 2010; KRUPEK, 2010; MINATTI-FERREIRA et al., 2006).

\section{MATERIAIS E MÉTODOS}

\section{Área de estudo}

A bacia hidrográfica do Córrego dos Pires, área de estudo deste trabalho, está situada no Município de Jaú, região centro-oeste do Estado de São Paulo, conforme se visualiza na figura 1. O Córrego dos Pires é um afluente da margem direita do Rio Jaú, que por sua vez é um afluente da margem direita do Rio Tietê, no Reservatório de Bariri, na Unidade de Gerenciamento de Recursos Hídricos do Tietê - Jacaré (UGRHI 13). 


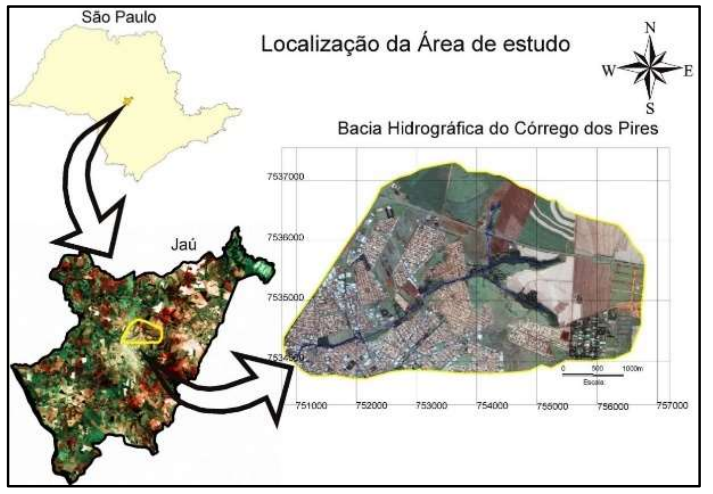

Figura 1: Mapa de localização e área de estudo da Bacia Hidrográfica do Córrego dos Pires, Jaú/SP.

A bacia está localizada entre as coordenadas UTM 7533455 e 7537231 N e 756880 e 750631 E. Possui área total de $15,45 \mathrm{~km}^{2}$, com altitude máxima de $655 \mathrm{~m}$ e mínima de $484 \mathrm{~m}$, sendo a altitude média de $585 \mathrm{~m}$ e a amplitude altimétrica de $171 \mathrm{~m}$. Sua rede de drenagem é composta por cinco canais, totalizando $7,44 \mathrm{~km}$ de extensão. De acordo com a classificação proposta por Strahler (1953), o Córrego dos Pires é um curso d'água de 20 ordem.

Os principais tipos de solo encontrados na bacia são: Latossolo Vermelho Distrófico; Latossolo Vermelho Eutroférrico; e o Nitossolo Vermelho Eutroférrico. Segundo classificação de Köeppen, seu clima é definido como Cwa, tropical de altitude com verão úmido e inverno seco e a precipitação anual varia de 1400 a 1500mm (AZEVEDO et al., 2012). O período chuvoso ocorre de outubro a março, sendo o trimestre mais chuvoso de dezembro a fevereiro. O período seco vai de abril a setembro, com o trimestre mais seco entre junho e agosto (REZENDE, 2010).

A bacia hidrográfica do Córrego dos Pires foi inicialmente dividida em cinco para a determinação dos trechos a serem avaliados, de acordo com o ilustrado na figura 2. As três primeiras áreas (1, 2 e 3) foram definidas pelos divisores de água dos segmentos originados a partir das nascentes localizadas nas cabeceiras, pela rodovia e pelo limite da zona efetivamente urbanizada. As duas áreas seguintes (4 e 5) foram determinadas a partir de barragem existente no talvegue principal. Uma área está localizada a montante e a outra a jusante do reservatório, conhecido no município como "Lago do Silvério".

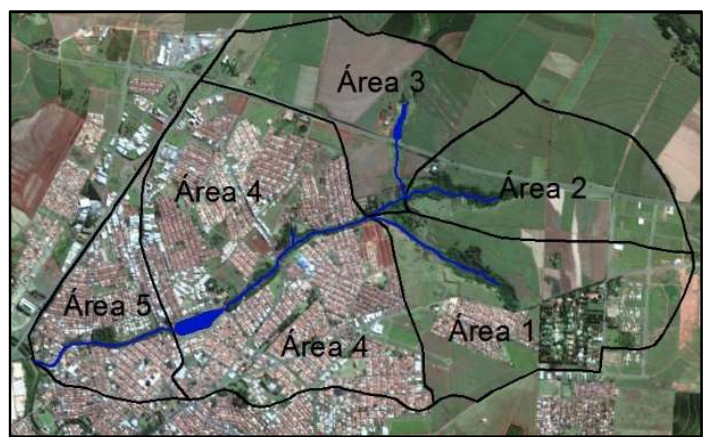

Figura 2: Zonas da Bacia Hidrográfica do Córrego dos Pires e indicação dos locais de amostragem, Jaú/SP.

A partir daí, foram escolhidos os trechos dos cursos d'água a serem avaliados de forma a abranger todas as áreas definidas para a bacia. Procurou-se cobrir a maior extensão possível da rede de drenagem, considerando sempre a facilidade de acesso. Os trabalhos de campo foram realizados nos meses de setembro e outubro de 2016 , sempre no período da manhã. 
Tiveram como objetivo principal verificar as condições atuais dos trechos visitados, classificando-os de acordo com os protocolos em seus níveis de preservação ou degradação. Os dados de posicionamento foram obtidos por intermédio de um aparelho de GPS Garmin, modelo eTrex Vista HCx. Além dele foram utilizadas planilhas para aplicação dos protocolos, trena, coletor de água e de substrato e máquina fotográfica.

A aplicação dos PARs foi realizada em doze trechos de cursos d'água da Bacia Hidrográfica do Córrego dos Pires, identificados pela letra ' $T$ ' e cinco nascentes, identificadas pela letra ' $N$ '. A localização média dos trechos e das nascentes avaliadas em relação à rede hídrica e às zonas urbanas consolidada, não consolidada e rural da bacia estão ilustradas na figura 3.

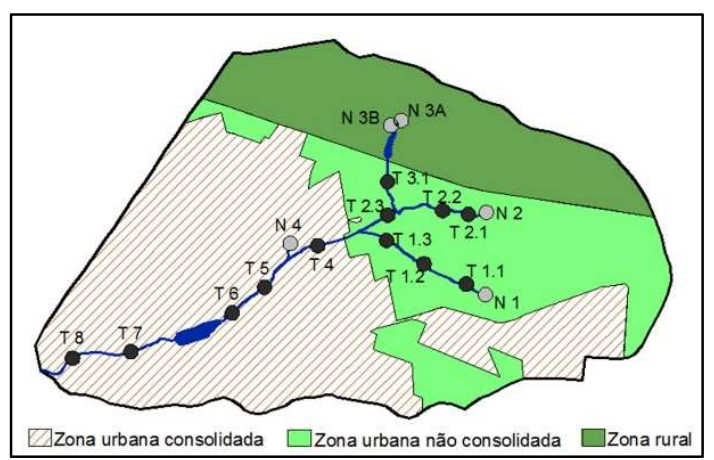

Figura 3: Usos do solo baseados na localização dos trechos denominados T1.1, T1.2, T1.3, T2.1, T2.2, T2.3, T3.1, T4, T5, T6, T7 e T8 e das nascentes N1, N2, N3A, N3B e N4 avaliados na Bacia Hidrográfica do Córrego dos Pires. Fonte: SÃO PAULO (2012).

$\mathrm{Na}$ análise macroscópica das nascentes, foi utilizado o PAR, proposto por Gomes et al. (2005). Este protocolo avalia treze parâmetros: cor da água; odor; resíduos sólidos ao redor; materiais flutuantes; espumas; óleos; esgoto; vegetação; uso antrópico; uso por animais; acesso; equipamentos urbanos; e tipo de área de inserção. Para cada parâmetro são possíveis três níveis de pontuação: ruim (1 ponto), médio (2 pontos) e bom (3 pontos). A somatória do valor atribuído a cada parâmetro na avaliação de campo, gera a pontuação final da nascente, que indicará seu grau de preservação em cinco categorias: "ótima", "boa", "razoável", "ruim" e "péssima" conforme mostra a Tabela 1.

Tabela 1: Classes de pontuação para avaliação do grau de preservação de nascentes.

\begin{tabular}{|c|c|}
\hline Grau de preservação & Pontuação final \\
\hline Ótima & Entre 37 e 39 pontos \\
\hline Boa & Entre 34 e 36 pontos \\
\hline Razoável & Entre 31 e 33 pontos \\
\hline Ruim & Entre 28 e 30 pontos \\
\hline Péssima & Abaixo de 28 pontos \\
\hline
\end{tabular}

Em seguida, foi realizada a avaliação para cada parâmetro, somando-se a pontuação obtida em cada nascente e comparando a somatória com a pontuação total a ser atingida caso o parâmetro obtivesse pontuação máxima em todas as nascentes. Dessa forma, foi possível verificar os parâmetros com os melhores e os piores desempenhos.

Para a análise dos trechos de rios a avaliação foi realizada de acordo com o protocolo proposto por Callisto et al. (2002), composto por duas planilhas. Este PAR é uma adaptação de outros dois protocolos. A 
primeira planilha é originária do protocolo proposto pela Agência de Proteção Ambiental de Ohio, EUA (USEPA, 1987), onde são avaliadas características dos trechos da bacia e os níveis de impactos ambientais decorrentes de ações antrópicas. Nesta planilha são avaliados dez parâmetros com pontuações que variam de 0 a 4 pontos. Trechos muito impactados recebem nota zero (0); trechos alterados recebem nota dois (2); e trechos naturais recebem nota quatro (4). Os parâmetros são: tipos de ocupação das margens; existência de processos erosivos; alterações antrópicas; cobertura vegetal no leito; odor, oleosidade e transparência da água; odor do sedimento; oleosidade do fundo; e tipo de fundo.

A segunda planilha do protocolo, proposta por Callisto et al. (2002), foi adaptada do protocolo utilizado por Hannaford et al. (1997), e procura avaliar as condições de habitats e nível de conservação em relação às condições naturais. Nesta planilha são avaliados doze parâmetros, com a pontuação variando entre 0 e 5 pontos, sendo: zero (0), dois (2), quatro (4) e cinco (5), onde o valor zero corresponde ao maior estado de degradação, e o valor cinco corresponde a degradação ausente. Os parâmetros são: tipos de fundo; extensão de rápidos; frequência de rápidos; tipos de substrato; deposição de lama; depósitos sedimentares; alteração no canal do rio; características do fluxo das águas; presença de mata ciliar; estabilidade dos taludes fluviais; extensão da mata ciliar; e presença de plantas aquáticas.

Devido à diferença entre as condições das margens direita e esquerda em um mesmo trecho do curso d'água, para parâmetros como, presença de mata ciliar, estabilidade dos taludes fluviais e outros relacionados as características das margens em alguns trechos, foram atribuídas pontuações diferentes para cada margem, sendo a pontuação do trecho no quesito obtida pela média das pontuações atribuídas.

A pontuação final do protocolo proposto por Callisto et al. (2002), é dada pela somatória das pontuações das duas planilhas de avaliação. A pontuação de cada planilha, por sua vez, é obtida pela somatória do valor atribuído a cada parâmetro na avaliação de campo. O resultado final indica o grau de preservação ou de degradação da área. Segundo o protocolo de Callisto et al. (2002) os trechos podem ser classificados como "impactado" (abaixo de 40 pontos), "alterado" (entre 41 e 60 pontos) e "natural" (acima de 61 pontos).

Essa classificação, entretanto, agrupa na mesma categoria, trechos com situações muito distintas em relação ao seu estado atual. Desta forma este trabalho propôs uma recategorização para o enquadramento dos trechos de curso d'água da bacia, ampliando o número de classes propostas por Callisto et al. (2002) de três para sete, pois esta nova classificação permite uma melhor distinção entre os trechos.

Tabela 2: Comparação das categorias de estado dos trechos de cursos.

\begin{tabular}{|c|c|c|c|}
\hline \multicolumn{4}{|c|}{ PROPOSTA } \\
\hline Pontuação & Class & & Pontuação \\
\hline 85 a 100 & Natural & \multirow{2}{*}{ Natural } & \multirow{2}{*}{$>61$} \\
\hline 61 a 84 & Seminatural & & \\
\hline 51 a 60 & Alterado & \multirow{2}{*}{ Alterado } & \multirow{2}{*}{41 a 60} \\
\hline 41 a 50 & Muito alterado & & \\
\hline 31 a 40 & Impactado & \multirow{3}{*}{ Impactado } & \multirow{3}{*}{0 a 40} \\
\hline 21 a 30 & Altamente impactado & & \\
\hline 0 a 20 & Degradado & & \\
\hline
\end{tabular}

Fonte: Callisto et al. (2002). 
As categorias propostas foram: 'natural' (de 85 a 110 pontos); 'seminatural' (de 61 a 84 pontos); 'alterado' (de 51 a 60 pontos); 'muito alterado' (de 41 a 50 pontos); 'impactado' (de 31 a 40 pontos); 'muito impactado' (de 21 a 30 pontos) e 'degradado' (de 0 a 20 pontos). A tabela 2 apresenta a comparação das categorias de estado dos trechos de cursos d'água definidos por Callisto et al. (2002) e o proposto pelo presente trabalho.

A condição de referência utilizada para classificar um trecho como "natural" foi a de um trecho de rio bem preservado, sem nenhuma ação antrópica, com mata ciliar em bom estado e com presença de regenerantes, margens conservadas e sem indícios de processos erosivos, sem acesso de animais domésticos, lançamento de efluentes e águas pluviais e livre de resíduos sólidos.

Para classificar um trecho como 'degradado', o pior grau estipulado, foi utilizado como referência um trecho de rio retificado ou canalizado, sem mata ciliar ou parques lineares, com a área de preservação ocupada por vias e/ou edificações, margens erodidas, com lançamento de efluentes sem tratamento e de águas pluviais sem amortecimento, com disposição de resíduos sólidos em quantidade, sendo denominado no linguajar popular 'esgoto a céu aberto'.

Para os graus intermediários foram definidas pontuações baseadas em uma escala, do "natural" ao "degradado". Cabe ressaltar que para determinar os gradientes de classificações, parte-se da premissa de que cursos d'água menos afetados pelas ações antrópicas apresentarão melhores estados de conservação e vice-versa. É importante para a aplicação do PAR estabelecer valores de referência em locais pouco perturbados que servirão de base para a classificação. (BARBOUR et al., 1999).

Para a avaliação da rede de drenagem da bacia para cada parâmetro, foi realizada uma ponderação, somando-se a pontuação obtida em cada trecho do curso d'água em relação a pontuação total a ser atingida, caso o parâmetro obtivesse pontuação máxima em todos os trechos. Desta forma foi possível verificar os parâmetros com os melhores e os piores desempenhos.

\section{RESULTADOS}

Foram avaliadas e localizadas as cinco nascentes identificadas no Córrego dos Pires (Tabela 3). Diversas áreas encharcadas e alguns afloramentos foram encontrados ao longo das margens do Córrego, porém sem caracterizar a formação de novos trechos de cursos d'água. Em relação ao grau de preservação das cinco nascentes, de acordo com a classificação proposta por Gomes et al. (2005), uma foi classificada como boa (nascente 2), uma como regular (nascente 4) e três como ruins (nascentes 1, 3A e 3B), conforme se nota na figura 4.

Tabela 3: Coordenadas UTM e altitudes das nascentes do Córrego dos Pires, Município de Jaú/SP. (Datum de referência: SIRGAS)

\begin{tabular}{|c|c|c|c|}
\hline Nascentes & Coordenada E & Coordenada N & Atitude (m) \\
\hline 1 & 755153 & 7534816 & 568 \\
\hline 2 & 755147 & 7535627 & 578 \\
\hline 3A & 754310 & 7536491 & 574 \\
\hline 3B & 754269 & 7536457 & 571 \\
\hline 4 & 753244 & 7535302 & 537 \\
\hline
\end{tabular}




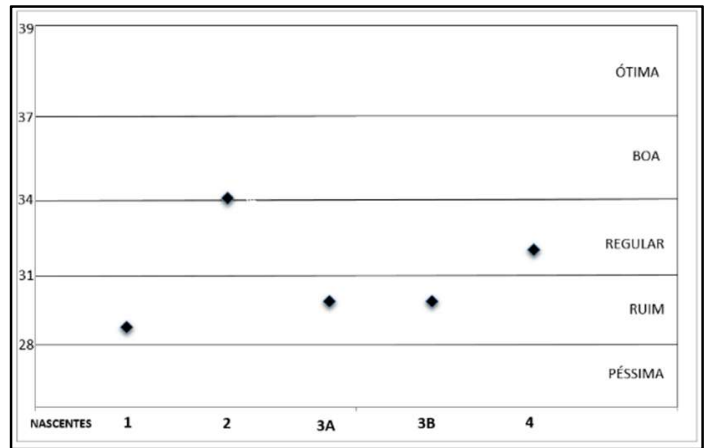

Figura 4: Classificação das nascentes do Córrego dos Pires, Jaú/SP, de acordo com o protocolo proposto por Gomes et al. (2005).

De acordo com os parâmetros utilizados na avaliação, alguns se apresentaram em maior conformidade do que outros, influenciando diretamente na pontuação final de cada nascente, conforme se idealiza na tabela 4, que propõe a Avaliação de desempenho dos parâmetros nas nascentes do Córrego dos Pires, Município de Jaú/SP de acordo com o protocolo proposto por Gomes et al. (2005).

Tabela 4: Avaliação de desempenho dos parâmetros nas nascentes do Córrego dos Pires, Município de Jaú/SP.

\begin{tabular}{|c|c|c|c|c|c|c|c|}
\hline \multirow{2}{*}{ PARÂMETROS } & \multicolumn{5}{|c|}{ Nascentes } & \multirow{2}{*}{$\begin{array}{l}\text { Pontuação } \\
\text { Máxima } \\
\text { por } \\
\text { Parâmetro }\end{array}$} & \multirow{2}{*}{$\begin{array}{l}\text { Pontuação } \\
\text { por } \\
\text { Parâmetro }\end{array}$} \\
\hline & 1 & 2 & 3A & 3B & 4 & & \\
\hline 1. Cor da água & 3 & 3 & 3 & 3 & 3 & & 15 \\
\hline 2. Odor & 3 & 3 & 3 & 3 & 3 & & 15 \\
\hline 3. Resíduos Sólidos ao redor & 1 & 3 & 2 & 2 & 3 & & 11 \\
\hline 4. Materiais flutuantes (RSU na água) & 3 & 3 & 3 & 3 & 3 & & 15 \\
\hline 5. Espumas & 3 & 3 & 3 & 3 & 3 & & 15 \\
\hline 6. Óleos & 3 & 3 & 2 & 2 & 3 & & 13 \\
\hline 7. Esgoto & 2 & 3 & 3 & 3 & 3 & 15 & 14 \\
\hline 8. Vegetação & 2 & 3 & 1 & 1 & 2 & & 9 \\
\hline 9. Usos antrópicos & 1 & 2 & 1 & 1 & 2 & & 7 \\
\hline 10. Uso por animais & 3 & 1 & 3 & 3 & 3 & & 13 \\
\hline 11. Acesso & 1 & 2 & 1 & 1 & 1 & & 6 \\
\hline 12. Equipamento urbanos & 2 & 3 & 3 & 3 & 2 & & 13 \\
\hline 13. Tipo de área de inserção & 2 & 2 & 2 & 2 & 1 & & 9 \\
\hline Pontuação Nascentes (Máx=39; Mín=13) & 29 & 34 & 30 & 30 & 32 & & \\
\hline
\end{tabular}

Fonte: Gomes et al. (2005).

Em relação aos trechos, dos doze avaliados, três estão na zona 1, dois na zona 2, dois na zona 3, três na zona 4 e dois na zona 5. A somatória da extensão dos trechos avaliados foi de $4,91 \mathrm{~km}$ de cursos d'água. Considerando-se que a rede de drenagem total da bacia é de $7,44 \mathrm{~km}$, foram avaliados $66 \%$ do total desta. A tabela 5 apresenta as coordenadas UTM iniciais, finais e a extensão de cada trecho.

Tabela 5: Coordenadas UTM iniciais, finais e a extensão de cada trecho do Córrego dos Pires avaliado. (Datum de referência: SIRGAS)

\begin{tabular}{|c|cc|cc|c|}
\hline \multirow{2}{*}{ Trechos } & \multicolumn{2}{|c|}{ Início } & \multicolumn{2}{c|}{ Fim } & \multirow{2}{*}{$\begin{array}{c}\text { Extensão } \\
\text { (km) }\end{array}$} \\
\cline { 2 - 5 } & Coordenada E & Coordenada N & Coordenada E & Coordenada N & 0,26 \\
$\mathbf{1 . 1}$ & 755153 & 7534816 & 754923 & 7534931 & 0,29 \\
$\mathbf{1 . 2}$ & 754643 & 7535047 & 754409 & 7535208 & 0,29 \\
$\mathbf{1 . 3}$ & 754409 & 7535208 & 754045 & 7535413 & 0,42 \\
$\mathbf{2 . 1}$ & 755074 & 7535583 & 754896 & 7535624 & 0,19 \\
$\mathbf{2 . 2}$ & 754852 & 7535623 & 754786 & 7535631 & 0,07 \\
$\mathbf{2 . 3}$ & 754353 & 7535653 & 753930 & 7535435 & 0,51 \\
$\mathbf{3 . 1}$ & 754211 & 7536034 & 754256 & 7535740 & 0,31 \\
$\mathbf{4}$ & 753930 & 7535435 & 753187 & 7535116 & 0,83 \\
$\mathbf{5}$ & 753103 & 7534991 & 752805 & 7534740 & 0,40 \\
$\mathbf{6}$ & 752805 & 7534740 & 752646 & 7534621 & 0,20 \\
$\mathbf{7}$ & 752141 & 7534387 & 751391 & 7534271 & 0,79 \\
$\mathbf{8}$ & 751391 & 7534271 & 750853 & 7534101 & 0,64 \\
\hline \hline
\end{tabular}

Quanto à avaliação do estado de preservação ou degradação dos trechos de cursos d'água, os resultados foram elaborados de acordo com as duas propostas: com três (CALLISTO et al., 2002) e com sete categorias. Segundo a classificação proposta por Callisto et al. (2002), dos doze trechos avaliados três foram 
enquadrados como naturais, quatro como alterados, cinco como impactados, como se propõe na figura 5 e na tabela 6.

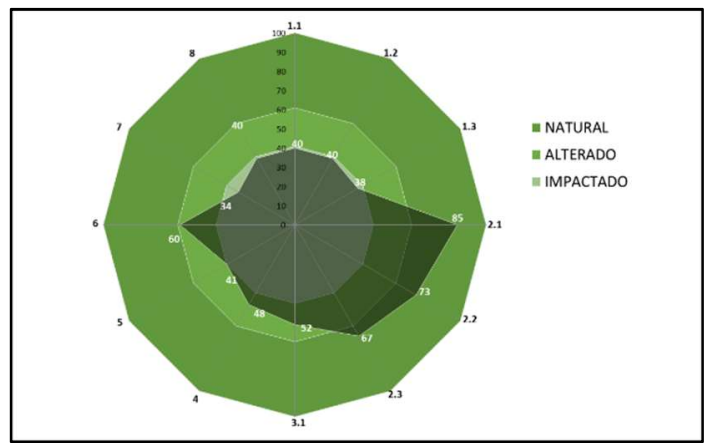

Figura 5: Classificação dos doze trechos dos cursos d’água da Bacia Hidrográfica do Córrego dos Pires.

Fonte: Callisto et al. (2002)

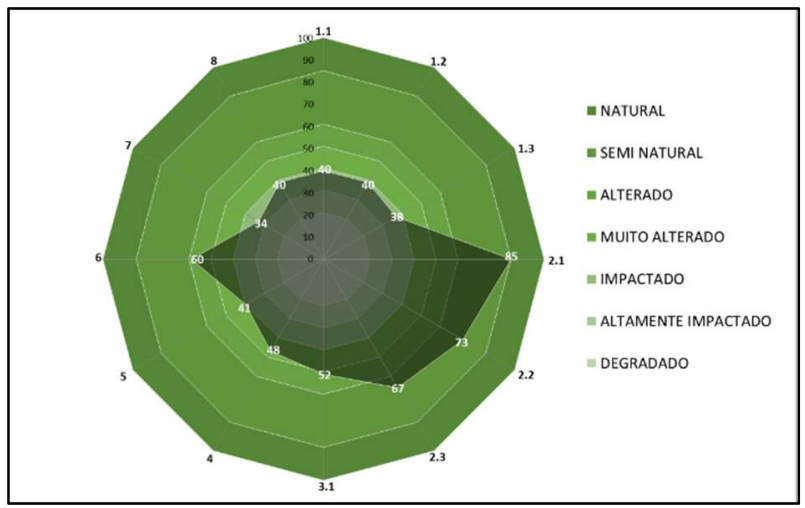

Figura 6: Classificação dos doze trechos dos cursos d'água da Bacia Hidrográfica do Córrego dos Pires de acordo com as classes propostas no trabalho.

Segundo a classificação proposta por este trabalho, dos doze trechos avaliados, um foi enquadrado como natural, dois como seminaturais, dois como alterados, dois como muito alterados e cinco como impactados, resultado esse trazido pela figura 6 e pela tabela 6 . A comparação entre as classificações de cada trecho de curso d'água de acordo com as duas propostas de classificação pode ser observada na tabela 6.

Tabela 6: Comparação das classificações dos trechos avaliados.

\begin{tabular}{|c|c|c|c|}
\hline TRECHOS & PONTUAÇÃO & CLASSIFICAÇÃo DE CALLISTO & $\begin{array}{c}\text { CLASSIFICAÇÃO } \\
\text { DO TRABALHO }\end{array}$ \\
\hline $\mathbf{1 . 1}$ & 40 & Impactado & Impactado \\
\hline 1.2 & 40 & Impactado & Impactado \\
\hline $\mathbf{1 . 3}$ & 38 & Impactado & Natural \\
\hline $\mathbf{2 . 1}$ & 85 & Natural & Seminatural \\
\hline $\mathbf{2 . 2}$ & 73 & Natural & Seminatural \\
\hline $\mathbf{2 . 3}$ & 67 & Natural & Alterado \\
\hline $\mathbf{3 . 1}$ & 52 & Alterado & Muito alterado \\
\hline $\mathbf{4}$ & 48 & Alterado & Alterado \\
\hline $\mathbf{5}$ & 41 & Alterado & Impactado \\
\hline $\mathbf{6}$ & 60 & Alterado & Impactado \\
\hline $\mathbf{7}$ & 34 & Impactado & Impactado \\
\hline $\mathbf{8}$ & 40 & &
\end{tabular}

Fonte: Callisto et al. (2002).

De forma geral, os parâmetros que mostraram melhor desempenho foram odor e oleosidade da água, odor e oleosidade de fundo e característica do fluxo das águas, obtendo quase sempre elevada pontuação. Já os parâmetros tipo de ocupação das margens, presença de erosões, cobertura vegetal, tipo de 
fundo, frequência dos rápidos, tipos de substratos e presença de plantas aquáticas obtiveram na maioria dos casos baixíssima pontuação. Na tabela 7, é possível visualizar a avaliação dos parâmetros de acordo com os trechos e seus percentuais de conformidade.

Tabela 7: Avaliação da conformidade dos parâmetros do protocolo de Callisto ao longo do Córrego dos Pires, município de Jaú/SP.

\begin{tabular}{|c|c|c|c|c|c|c|c|c|c|c|c|c|c|c|}
\hline \multirow[b]{2}{*}{ PARÂMETROS } & \multicolumn{11}{|c|}{ Trechos } & \multirow{2}{*}{$\begin{array}{c}\text { Pontuaçāo } \\
\text { por } \\
\text { parâmetro }\end{array}$} & \multirow{2}{*}{$\begin{array}{c}\text { Pontuação } \\
\text { máxima }\end{array}$} & \multirow{2}{*}{\begin{tabular}{|c|} 
Conformidade \\
do parâmetro \\
no Córrego \\
$(\%)$
\end{tabular}} \\
\hline & 1.1 & 1.21 & & & 2.2 & 2.3 & 3.1 & 4 & 5 & 6 & & & & \\
\hline 1. Tipo de ocupação das margens do corpo d'água & 2 & 2 & 2 & 4 & 2 & 2 & 2 & 0 & 2 & 2 & 100 & 21 & \multirow{4}{*}{$\begin{array}{c}\text { Parâmetros } \\
\text { a } 10\end{array}$} & $44 \%$ \\
\hline 2. Erosão nas margens do rio e assoreamento do leito & 0 & 0 & 0 & 4 & 2 & 4 & 4 & 2 & 2 & $2 \mid$ & 0 & 22 & & $46 \%$ \\
\hline 3. Alteraçöes antrópicas & 2 & 2 & 2 & 4 & 4 & 2 & 0 & 2 & 2 & 2 & 2 & 26 & & $54 \%$ \\
\hline 4. Cobertura vegetal no leito & 0 & 0 & 0 & 4 & 4 & 0 & 2 & 0 & 1 & 0 & 5 & 11 & & $23 \%$ \\
\hline 5. Odor da água & 4 & 4 & 4 & 4 & 4 & 4 & 4 & 4 & 3 & 4 & 2 & 43 & \multirow{2}{*}{$\begin{array}{l}\text { de } 0 \text { a } 4 \\
\text { pontos }\end{array}$} & $90 \%$ \\
\hline 6. Oleosidade da água & 4 & 4 & 4 & 4 & 4 & 4 & 4 & 4 & 2 2 & 4 & 4 & 46 & & $96 \%$ \\
\hline 7. Transparência da água & 4 & 2 & 2 & 4 & 4 & 3 & 4 & 2 & 2 & 2 & 2 & 33 & \multirow{4}{*}{\begin{tabular}{|c} 
Pontuaçāo \\
máxima \\
48
\end{tabular}} & $69 \%$ \\
\hline 8. Odor do sedimento (fundo) & 4 & 4 & 4 & 4 & 4 & 4 & $4{ }_{4}$ & 4 & \begin{tabular}{l|l}
4 \\
\end{tabular} & 4 & 2 & 44 & & $92 \%$ \\
\hline 9. Oleosidade do fundo & 4 & 4 & 4 & 4 & 4 & 4 & 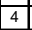 & 4 & 2 & 4 & 4 & 46 & & $96 \%$ \\
\hline 10. Tipo de fundo & 2 & 2 & 2 & 2 & 2 & 2 & 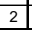 & 2 & 2 & 4 & 3 & 28 & & $58 \%$ \\
\hline 11. Tipos de fundo & 0 & 0 & 0 & 4 & 4 & 4 & 0 & 2 & 2 & $2 \mid$ & 0 & 18 & \multirow{6}{*}{$\begin{array}{c}\text { Parâmetros } \\
11 \text { a } 22 \\
\text { de } 0 \text { a } 5 \\
\text { pontos }\end{array}$} & $38 \%$ \\
\hline 12. Extensão dos Rápidos & 0 & 2 & 2 & 4 & 2 & 2 & 0 & 2 & 2 & 4 & 244 & 26 & & $54 \%$ \\
\hline 13. Frequência dos Rápidos & 0 & 0 & 0 & 2 & 2 & 2 & \begin{tabular}{|l|l|l|}
0 & \\
\end{tabular} & 2 & $2 \mid$ & $2 \mid$ & $2 \sqrt{5}-3 x-3 x$ & 19 & & $40 \%$ \\
\hline 14. Tipos de substratos & 0 & 0 & 0 & 0 & 0 & 0 & 0 & 0 & 0 & $2 \mid$ & 0 & 2 & & $4 \%$ \\
\hline 15. Deposição de lama & 2 & 2 & 2 & 5 & 5 & 5 & 5 & 4 & 1 & 4 & 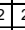 & 39 & & $81 \%$ \\
\hline 16. Depósito sedimentares & 0 & 0 & 0 & 5 & 4 & 4 & 5 & 2 & 0 & $2 \mid$ & & 24 & & $50 \%$ \\
\hline 17. Alteração no canal do rio & 2 & 4 & 4 & 5 & 5 & 4 & 4 & 4 & $2 \mid$ & 4 & 0 & 40 & \multirow{6}{*}{$\begin{array}{c}\text { Pontuacạāo } \\
\text { máxima } \\
60\end{array}$} & $83 \%$ \\
\hline 18. Caracteristicas do fluxo das águas & 2 & 4 & 4 & 5 & 5 & 4 & 4 & 4 & 2 & $2 \mid$ & & 42 & & $88 \%$ \\
\hline 19. Presença de mata ciliar & 4 & 2 & 0 & 5 & 3 & 3 & 0 & 0 & 2 & 4 & 2 & 25 & & $52 \%$ \\
\hline 20. Estabilidade das margens & 0 & 0 & 0 & 5 & 5 & 4 & 4 & 2 & 2 & 2 & & 26 & & $54 \%$ \\
\hline 21. Extensão de mata ciliar & 4 & 2 & 2 & 5 & 4 & 4 & 0 & 2 & 44 & 4 & 2 & 33 & & $69 \%$ \\
\hline 22. Presença de plantas aquáticas & 0 & 0 & 0 & 2 & 0 & 2 & 0 & 0 & 0 & 0 & & 4 & & $8 \%$ \\
\hline Pontuação por trecho (Máximo $=100$ & 40 & & & & & 67 & & 48 & & 600 & 4 & & & \\
\hline
\end{tabular}

Fonte: Callisto et al. (2002).

\section{DISCUSSÃO}

Os resultados apresentados indicam um processo de perda da integridade ecológica do Córrego dos Pires, de suas nascentes, áreas úmidas lindeiras e de suas margens. Um dos principais problemas que afetam os cursos d'água no Brasil é o lançamento de esgotos "in natura", ou seja, sem tratamento prévio. Muito embora possam existir lançamentos de esgoto doméstico clandestino no Córrego dos Pires, este fator não é significativo e não justifica os problemas encontrados, visto que o município de Jaú trata praticamente todo o esgoto doméstico gerado na zona urbana. Esta afirmação pode ser comprovada pelo elevado desempenho dos parâmetros, tanto no protocolo de nascentes quanto no de rios, relacionados a este tema (esgoto, odor, transparência, oleosidade, espuma e outros).

Em relação as nascentes, a identificada como número 1 foi a diagnosticada em pior estado de conservação, tendo sido classificada como 'ruim'. Esta nascente encontra-se localizada em área periurbana. Seus principais problemas estão relacionados à concentração de águas pluviais da drenagem urbana e à existência de uma voçoroca a montante, a qual tem sido utilizada para a disposição de resíduos da construção civil sem qualquer tipo de controle sobre o que está sendo depositado; e sem que nenhum procedimento técnico para a recuperação ou estabilização da voçoroca tenha sido implementado.

Fica evidente na nascente e nos trechos a jusante a deposição de partículas de solo e de toda a espécie de resíduos sólidos, não apenas da construção civil, mas também de origem doméstica e até industrial. A nascente é impactada ainda devido ao fácil acesso e a conservação de solo ineficiente na zona rural que a cerca.

A nascente número 2 é a que se encontra em melhor condição, tendo sido classificada como "boa" em relação ao grau de preservação. Apresentou pontuação máxima em nove dos treze parâmetros do 
protocolo. Sua mata ciliar ocupa uma área superior à delimitada pela legislação ambiental vigente no que diz respeito a área de preservação permanente (APP) de nascentes.

O fragmento florestal, apesar de apresentar dossel contínuo e regenerantes, apresenta baixa diversidade de espécies (SAN MARTIN et al., 2013). Seu maior problema está relacionado à presença de bovinos e equinos, visto que a nascente está inserida em uma área de pastagem e não existe isolamento entre o pasto e o fragmento.

As nascentes 3A e 3B estão localizadas na zona rural da bacia hidrográfica do Córrego dos Pires e encontram-se bem próximas uma da outra, nas mesmas condições ambientais. Ambas foram classificadas como 'ruins', porém com pontuação superior a nascente 1 , muito embora no que diz respeito à vegetação remanescente, a nascente 1 esteja em melhor condição. Por ocasião, durante a atividade de campo para a aplicação do protocolo, toda a vegetação da área a montante e nas vertentes laterais das nascentes encontravam-se queimadas devido a ocorrência de um incêndio recente. Estas nascentes, bem como a nascente 2, são muito susceptíveis a este tipo de ocorrência devido à proximidade da rodovia.

A nascente 4 está inserida em área urbana consolidada e ainda assim apresentou a segunda melhor classificação das cinco analisadas ('regular'). Esta nascente não consta em nenhum dos trabalhos acadêmicos consultados, muito embora exista na área um sistema de captação de água desativado, que era utilizado outrora para o abastecimento público. A nascente apresenta mata ciliar em bom estado de conservação, porém o acesso a área é muito fácil.

No que diz respeito aos trechos dos cursos d'água, os piores resultados foram apresentados pelos trechos $1.1 ; 1.2 ; 1.3 ; 7$ e 8, classificados como 'impactados'. Nos trechos 1.1; 1.2; 1.3, embora a transparência da água fosse total no momento da avaliação e exista mata ciliar, o assoreamento decorrente da voçoroca a montante da nascente 1 é o fator potencializador da deterioração da integridade ecológica dos ecossistemas aquáticos e de transição nestes locais. Nestes trechos, todos os parâmetros que receberam baixa pontuação estão relacionados à erosão e ao assoreamento.

Nos trechos 7 e 8, localizados na zona urbana consolidada, além dos parâmetros relacionados à erosão, a instabilidade dos taludes fluviais, que é severa no trecho 7 e moderada no 8 , somada à presença de resíduos sólidos em grandes quantidades em ambos os trechos, contribuíram de forma significativa para a baixa pontuação dos mesmos. 0 trecho 7, a jusante do reservatório conhecido como 'Lago do Silvério' foi o que obteve a menor pontuação entre todos os trechos e o trecho 8, que se estende até a foz do córrego no Rio Jaú, é o único no qual as duas margens estão ocupadas por vias e edificações. Estes dois trechos, foram os únicos a apresentar odor na água e nos sedimentos do fundo, provavelmente devido ao lançamento de esgotos clandestinos.

Os trechos 4 e 5, classificados como muito alterados, além de apresentarem baixa pontuação nos parâmetros relacionados ao assoreamento, mostraram também problemas relacionados à instabilidade dos taludes fluviais. Esta baixa pontuação relacionada a estes parâmetros em toda a extensão urbana do córrego é consequência do aumento do escoamento superficial devido ao processo de impermeabilização do solo na bacia e a ineficiência e/ou inexistência dos sistemas de drenagem. 
O trecho com maior pontuação inserido em área urbana consolidada foi o número 6 , que foi classificado como 'alterado', porém com pontuação muito próxima a classe superior ('seminatural'). As margens do trecho são ocupadas por mata ciliar em bom estado de conservação. Apesar disto o trecho apresenta problemas com deposição de sedimentos pela proximidade da barragem do reservatório e instabilidade dos taludes fluviais, assim como os demais trechos da zona urbana, contrariando a ideia comum que a presença de vegetação nas margens é suficiente para a estabilidade dos taludes fluviais, como afirmam, por exemplo Barrela et al. (2001). O principal problema do trecho 3.1 é a ausência de mata ciliar em toda a sua extensão e em ambas as margens. A área de APP do trecho está tomada por gramíneas invasoras das espécies Urochloa decumbens (capim braquiária), Paspalum notatum (capim colonião) e Pennisetum purpureum (capim napier).

Os trechos 2.1, 2.2 e 2.3 foram os que apresentaram melhores condições de preservação, atingindo 85, 73 e 67 pontos, respectivamente. Estes trechos estão localizados no curso superior da nascente 2 e são o único exemplo na bacia do Córrego dos Pires que condiz com Vestena et al. (2006), quando relatam que, normalmente, o curso superior dos rios em uma bacia são os que apresentam melhor estado de preservação. O trecho 2.1 foi classificado como "natural" e os trechos 2.2 e 2.3 como 'seminaturais'. Uma das principais diferenças observadas entre o trecho 2.1 e os trechos 2.2 e 2.3 diz respeito à infestação da espécie exótica invasora Hedychium coronarium, conhecida popularmente como 'lírio-do-brejo', planta nativa da Ásia, que forma touceiras em córregos e áreas úmidas (ZENNI et al., 2011).

O trecho 2.1 ('natural') e a nascente 2 (grau de preservação 'bom' podem servir como padrão de referência, conforme proposto por Barbour et al. (1999) respectivamente para a recuperação dos trechos 1.1, 1.2 e 3.1 e para as nascentes 1 , 3A, 3B e 4 . Os trechos 1.1, 1.2 e 3.1 estão localizados em zona urbana não consolidada, nas cabeceiras da bacia.

Os parâmetros tipos de substrato e presença de plantas aquáticas foram os mais pontuados com o valor zero, que corresponde ao maior estado de degradação. Em relação ao tipo de substrato a baixa pontuação decorreu da constatação de que a maior parte do fundo dos trechos avaliados é lamoso.

A ausência de plantas aquáticas e musgos na maioria dos trechos provavelmente é consequência da instabilidade de todo sistema fluvial, em especial dos taludes e do fundo devido às alterações promovidas no escoamento superficial da bacia. A impermeabilização do solo devido a urbanização causa uma redução no volume de água que infiltra no mesmo. Segundo Bernhardt et al. (2005, citado por KRUPEK, 2010), isto leva a flutuações imprevisíveis do nível d'água em épocas de chuvas levando a sérios problemas de erosão, carreamentos e assoreamento de cursos d'água.

Este fator acarreta em um aumento do escoamento superficial significativo, capaz de elevar as vazões médias de cheia. Somado a isto, os sistemas de drenagem urbana tornam o fluxo da água mais rápido, reduzindo seu tempo de deslocamento até sair da bacia hidrográfica e antecipando seus picos de vazões máximas (TUCCl et al., 2006). Estes processos impossibilitam a fixação destes organismos, empobrecendo e simplificando os hábitats do ecossistema fluvial. 
O modelo de classificação proposto no presente trabalho possibilitou a classificação de trechos com características distintas em diferentes categorias. Por exemplo, os trechos $2.1,2.2$ e 2.3 , segundo a classificação proposta por Callisto et al. (2002), estariam enquadrados na mesma categoria ('natural'). Já de acordo com a nova classificação foi possível destacar o melhor estado de conservação encontrado no trecho 2.1, classificado como 'natural', enquanto os trechos 2.2 e 2.3 foram classificados como 'seminaturais'. A ampliação das categorias proposta por Callisto et al. (2002), portanto, permitiu uma classificação mais fiel a realidade encontrada no córrego.

Em relação a aplicação da ferramenta surgiram dúvidas interpretativas e divergências quanto à pontuação de determinados parâmetros, principalmente nos itens constantes da segunda planilha proposta por Callisto et al. (2002). Lobo et al. (2011) e Bizzo et al. (2014) citam em seus trabalhos que a utilização dos protocolos por pessoas sem conhecimento na área de ecologia de rios, podem gerar resultados imprecisos e pouco confiáveis.

Outra questão que deve ser ressaltada é que a aplicação dos PARs de maneira a abranger toda a rede hídrica da bacia produz diagnósticos mais confiáveis, que funcionam melhor como ferramentas de apoio à tomada de decisões, como fundamenta Otsuka (2013). Além disso, é importante considerar que, por se tratar de uma análise macroscópica, algumas informações, principalmente referentes a qualidade físico-química, biológica e sanitária da água, não são avaliadas. Fasola (2011) em seu trabalho, complementou a análise macroscópica realizada através da aplicação dos PARs com a realização de análises físico-químicas e biológicas de qualidade da água dos corpos hídricos e obteve resultados satisfatórios.

\section{CONCLUSÕES}

Os resultados demonstraram a eficácia dos protocolos de nascentes e rios utilizados na avaliação ambiental da bacia hidrográfica do Córrego dos Pires. A categorização proposta pelo trabalho permitiu classificar o estado de cada trecho, enquadrando na mesma categoria apenas os trechos em situações semelhantes. As situações encontradas e a classificação quanto aos impactos ambientais macroscópicos nas nascentes e em cada trecho dos cursos d'água permitiram o diagnóstico da situação atual de toda a extensão da rede de drenagem da bacia. Estas informações são fundamentais para o planejamento das ações a serem efetivadas, visando a melhoria da qualidade ambiental da bacia e a recuperação da integridade ecológica dos ecossistemas fluviais.

A aplicação dos PARs se mostrou eficiente para a classificação do grau de preservação ou de degradação dos trechos analisados e na identificação de seus principais problemas. Entretanto, por se tratar de uma análise macroscópica algumas informações, principalmente referentes a qualidade físico-química, biológica e sanitária da água, não são avaliadas, podendo encobrir por exemplo, possíveis focos de contaminação.

Outro aspecto relevante é que a utilização dos protocolos como ferramenta de apoio a tomada de decisão para a gestão ambiental urbana depende de mão-de-obra qualificada, pois apesar dos protocolos apresentarem linguagem simples e fácil manuseio, é necessário conhecimento prévio em relação aos 
parâmetros do protocolo, que por sua vez dependem da interpretação dos processos da ecologia de rios, das ciências das águas e da engenharia ambiental e sanitária para que não haja distorções e equívocos na pontuação das planilhas.

Em relação ao estudo de caso, foi possível verificar que a rede hídrica da bacia hidrográfica do Córrego dos Pires não apresenta nenhum trecho nas categorias 'altamente impactado' e 'degradado'. Apesar dos resultados indicarem uma situação preocupante, ações como restauração da vegetação nas nascentes, revitalização do leito do córrego e de suas margens, controle e recuperação das áreas erodidas, adoção de sistemas de drenagem eficientes e sustentáveis e de programas de educação ambiental, tendo em vista os problemas observados em relação à disposição inadequada de resíduos sólidos nas margens, vias, terrenos ao longo da rede hídrica e em toda a bacia; podem reverter o cenário atual.

\section{REFERÊNCIAS}

AZEVEDO, P. F. F.; REZENDE, J. H.; VENIZIANI JR, J. C. T.; FAXINA, R. R. C.. Ocupação de fundos de vale da Bacia Hidrográfica do Córrego dos Pires - Jaú/SP. In SIMPÓSIO DE MEIO AMBIENTE E RECURSOS HÍDRICOS, 4. Anais. São Carlos: Rima Editora, p.103-118, 2012.

BARBOUR, M. T.; GERRITSEN, J.; SNYDER, B. D.; STRIBLING, J. B.. Rapid Bioassessment Protocols for Use in Streams and Wadeable Rivers: Periphyton, Benthic Macroinvertebrates and Fish. 2 ed. Washington: USEPA, 1999.

BARRELA, W.; PETRERE JUNIOR, M.; SMITH, W. S.; MONTAG. L. F. A.. As relações entre as matas ciliares, os rios e os peixes. In: RODRIGUES, R. R.; LEITÃO FILHO, H. F.. Matas Ciliares: conservação e recuperação. São Paulo: EDUSP, 2001. p.1187-1207.

BIZZO, M. R. O.; MENEZES, J.; ANDRADE, S. F.. Protocolos de avaliação rápida de rios (PAR). Caderno de Estudos Geoambientais, v.4, n.1, p.5-13, 2014.

BUSS, D. F.; BAPTISTA, D. F.; NESSIMIAN, J. L.. Bases conceituais para a aplicação de biomonitoramento em programas de avaliação da qualidade da água de rios. Caderno de Saúde Pública, Rio de Janeiro, v.19, n.2, p.465473, 2003.

CALLISTO, M.; FERREIRA, W. R.; MORENO, P.; GOULART, M.; PETRUCIO, M.. Aplicação de um protocolo de avaliação rápida da diversidade de habitats em atividades de ensino e pesquisa (MG-RJ). Acta Limnológica Brasileira, v.14, n.1, p.91-98, 2002.

CALLISTO, M.; MORENO, P.; BARBOSA, F. A. R.. Habitat diversity and benthic functional trophic groups Serra do Cipó, Southeast Brazil. Revista Brasileira de Biologia, v.61, n.2, p.259-266, 2001.

CARVALHO, E. M.; RUSSO, M. G.; NAKAGAKI, J. M.. Utilização de um protocolo de avaliação rápida da diversidade de habitats em ambientes lóticos. Revista Ibero-Americana de Ciências Ambientais, Aquidabã, v.5, n.1, p.129-139, 2014.

FARIA, K. R. M.; GONÇALVES, R. C.; FALEIRO, M. V.; FALEIRO, J. H.; MALAFAIA, G.. Aplicação de um Protocolo de Avaliação Rápida de Rios na Caracterização da Qualidade Ambiental do
Ribeirão Laranjal, Pires do Rio/GO. Enciclopédia Biosfera, Goiânia, v.9, n.17, p.247-261, 2013.

FASOLA, G. B.. Protocolo de Avaliação Rápida da integridade de cursos d'água em áreas urbanas a partir da análise de variáveis físico-químicas e biológicas da água. Monografia (Graduação em Engenharia Sanitária e Ambiental) - Universidade Federal de Santa Catarina, Santa Catarina, 2011.

FAXINA, R. R. C.; REZENDE, J. H.; VENIZIANI JÚNIOR, J. C. T.; AZEVEDO, P. F. F.. Urbanização e alterações morfométricas e hidrológicas na bacia hidrográfica do Córrego dos Pires, Jaú, São Paulo. Revista Ibero-Americana de Ciências Ambientais, Aquidabã, v.3, n.2, p.57-72, 2012.

FIRMINO, P. F.; MALAFAIA, G.; RODRIGUES, A. S. L. Diagnóstico da integridade ambiental de trechos de rios localizados no município de Ipameri, sudeste do estado de Goiás, através de um protocolo de avaliação rápida. Brazilian Journal Aquatic Science and Technology, v.15, n.2, p.1-12, 2011.

FOGAROLI, R. I.. Erosão pluvial como geoindicador no monitoramento ambiental de bacias hidrográficas: estudo em Jaú (SP). Monografia (Graduação em Engenharia Ambiental) - Universidade de São Paulo, São Carlos, 2013.

GOMES, P. M.; MELO, C.; VALE, V. S.. Avaliação dos impactos ambientais em nascentes na cidade de Uberlândia-MG: Análise Macroscópica. Revista Sociedade e Natureza, Uberlândia, v.17, n.32, p.103-120, 2005.

GORSKI, M. C. B.. Rios e cidades: ruptura e reconciliação. São Paulo: Senac, 2010.

HANNAFORD, M. J.; BARBOUR, M. T.; RESH, V. H.. Training reduces observer variability in visual-based assessments of stream habitat. Journal of the North American Benthological Society, v.4, p.853-860, 1997.

HENRIQUES NETO, D.. Proposta de metodologia para avaliação de alternativas de revitalização de cursos d'água urbanos. Monografia (Graduação em Engenharia Sanitária e Ambiental) - Universidade Federal de Santa Catarina, Florianópolis, 2010. 
KRUPEK, R. A.. Análise comparativa entre duas bacias hidrográficas utilizando um protocolo de avaliação rápida da diversidade de habitats. Ambiência, v.6, n.1, p.147-158, 2010.

LOBO, E. A.; VOOS, J. G.; ABREU JÚNIOR, E. F.. Utilização de um protocolo de avaliação rápida de impacto ambiental em sistemas lóticos do Sul do Brasil. Caderno de Pesquisa, Santa Cruz, v.23, n.1, p.18-33, 2011

MINATTI-FERREIRA, D. D.; BEAUMORD, A. C.. Adequação de um protocolo de avaliação rápida de integridade ambiental para ecossistemas de rios e riachos: aspectos físicos. Revista Saúde e Ambiente, v.7, n.1, p.39-47, 2006.

OLIVEIRA, F. M.; NUNES, T. S.. Aplicação de protocolo de avaliação rápida para caracterização da qualidade ambiental do manancial de captação (Rio Pequeno) do município de Linhares, ES. Natureza online, v.13, n.2, p.86-91, 2015.

OTSUKA, C. Y.. Avaliação de protocolo de avaliação rápida no Córrego Água Espraiada, São Paulo/SP. Monografia (Graduação em Engenharia Sanitária e Ambiental) Universidade Federal de Santa Catarina, Florianópolis, 2013.

RADTKE, L.. Protocolos de Avaliação Rápida: Uma ferramenta de avaliação participativa de cursos d'água urbanos. Dissertação (Mestrado em Engenharia Civil) Universidade Federal de Santa Maria, Santa Maria, 2015.

REBOUÇAS, A. C.. Água Doce no Mundo e no Brasil. In: REBOUÇAS, A. C.; BRAGA, B.; TUNDISI, J. G.. Águas Doces no Brasil: capital ecológico, uso e conservação. São Paulo: Escrituras, 2006. p.1-37.

REZENDE, J. H.; PIRES, J. S. R.; MENDIONDO, E. M.. Hydrologic pulses and remaining natural vegetation in Jaú and Jacaré-Pepira watersheds. Brazilian Archives of Biology and Technology, v.53, p.1127-1136, 2010. DOI: http://doi.org/10.1590/S1516-89132010000500017

RODRIGUES, A. S. L.; CASTRO, P. T. A.. Adaptation of a rapid assessment protocol for rivers on rocky meadows. Acta Limnológica Brasileira, v.20, n.4, p.291-303, 2008.

RODRIGUES, A. S. L.; MALAFAIA, G.; CASTRO, P. T. A.. Protocolos de avaliação rápida de rios e a inserção da sociedade no monitoramento dos recursos hídricos. AmbiAgua, Taubaté, v.3, n.3, p.143-155, 2008. DOI: http://dx.doi.org/10.4136/ambi-agua.68
RODRIGUES, A. S. L.; MALAFAIA, G.; COSTA, A. T.; NALINIJÚNIOR, H. A.. Adequação e avaliação da aplicabilidade de um Protocolo de Avaliação Rápida na bacia do rio Gualaxo do Norte, Leste-Sudeste do Quadrilátero Ferrífero (MG, Brasil). Ambi-Agua, Taubaté, v.7, n.2, p.231-244, 2012. DOI: http://doi.org/10.4136/ambi-agua.872

SAN MARTIN, S. G. H.; MOREIRA, F. C.; MAZZIERO, F. F. F.; CARBONI, M.. Árvores, arbustos e trepadeiras da floresta ribeirinha do Córrego dos Pires, Jaú-SP. In: SIMPÓSIO DE MEIO AMBIENTE E RECURSOS HÍDRICOS, 5. Anais. São Carlos: Rima Editora, 2013.

SÃO PAULO. Lei Complementar n.443 de 14 de novembro de 2012. Revisa a Lei Complementar n.298 de 2007 e dispõe sobre o zoneamento, o parcelamento, o uso e a ocupação do solo no Município de Jahu e dá outras providências. Jaú: DOE, 2012.

SELLES, I. M.; VARGAS, A. V.; RIKER, F.; BAHIENSE, G.; RIOS, J. P.; CUNHA, L.; CAMPAGNANI, S.; MATTA, V.; BINDER, W.; ARAÚJO, Z.. Revitalização de rios: orientação técnica. Rio de Janeiro: SEMADS, 2001.

STRAHLER, A. N.. Hypsometric (area-altitude) analysis and erosional topography. Geological Society of America Bulletin, v.63, p.1117-1142, 1953.

TOLEDO, L. G.; NICOLELLA, G.. Índice de qualidade de água em microbacia sob uso agrícola e urbano. Scientia Agricola, v.59, n.1, p.181-186, 2002.

TUCCI, C. E. M.; MENDES, C. A.. Avaliação ambiental integrada de bacia hidrográfica. Brasília: MMA, 2006. USEPA. United States Environmental Protection Agency. Surface water monitoring: A framework for change. Washington: USEPA, 1987.

VARGAS, J. F. A.; FERREIRA JUNIOR, P. D.. Aplicação de um Protocolo de Avaliação Rápida na Caracterização da Qualidade Ambiental de duas Microbacias do Rio Guandu, Afonso Cláudio/ES. Revista Brasileira de Recursos Hídricos, v.17, n.1, 2012, p.161-168.

VESTENA, L. R.; THOMAZ, E. L.. Avaliação de conflitos entre áreas de preservação permanentes associadas aos cursos fluviais e o uso da terra na bacia do Rio das Pedras.

Ambiência, Guarapuava, v.2, n.1, p.73-85, 2006.

ZENNI, R. D.; ZILLER, S. R.. An overview of invasive plants in Brazil. Revista Brasileira de Botânica. v.34, n.3, p.431-46, 2011. 